\title{
ANÁLISE DAS CARACTERÍSTICAS FÍSICO-QUÍMICAS E ORGANOLÉPTICAS DE SABONTES LIQUÍDOS INTÍMOS FEMININOS
}

\author{
Noelma de Sousa Felix ${ }^{1}$ \\ Luciano Pereira Cabral ${ }^{2}$ \\ Wendel Simões Fernandes ${ }^{3}$ \\ Simone Aparecida de Biazzi Lapena ${ }^{4}$
}

Resumo: Os sabonetes íntimos líquidos femininos são produtos destinados à higienização da região intima e segundo a ANVISA são classificados como produtos de risco potencial, pois eles podem facilmente desequilibrar a flora vaginal e ocasionar vulvovaginites. Neste estudo, foram analisadas as características físico-químicas, organolépticas e testes de centrifugação, de seis amostras de sabonetes líquidos íntimos femininos de abrangência nacional e comercialização local. De forma geral, constatou-se que apenas duas das amostras analisadas não apresentaram resultado satisfatório, as demais amostras apresentaram características físico-químicas ( $\mathrm{pH}$, índice de espuma) e organolépticas (cor, odor e consistência), adequadas a comercialização, atendendo aos parâmetros fisiológicos e apresentando aceitação pelo mercado consumidor (BEZERRA et al., 2016).

Palavra-chave: Sabonetes líquidos; Região íntima; pH; Higienização.

\footnotetext{
${ }^{1}$ Farmácia Generalista/ Instituto Taubaté de Ensino Superior, Brasil. E-mail: noelmafelixdeus@hotmail.com.

${ }^{2}$ Farmácia Generalista/ Instituto Taubaté de Ensino Superior, Brasil. E-mail: saudebrasilnatural@gmail.com.

${ }^{3}$ Farmácia Generalista/ Instituto Taubaté de Ensino Superior, Brasil. E-mail: wen_sfernandes@hotmail.com.

${ }^{4}$ Farmácia Generalista/ Instituto Taubaté de Ensino Superior, Brasil. E-mail: professorasimonelapena@gmail.com.
} 